03;04

\title{
Плазменные и газодинамические приэлектродные процессы в начальной фазе микроструктурированного искрового разряда в воздухе
}

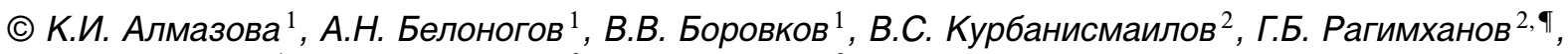 \\ А.А. Тренькин ${ }^{1}$, Д.В. Терешонок ${ }^{3}$, 3.Р. Халикова ${ }^{2}$ \\ ${ }^{1}$ Российский федеральный ядерный центр - Всероссийский научно-исследовательский институт экспериментальной \\ физики, Саров, Россия \\ 2 Дагестанский государственный университет, Махачкала, Россия \\ ${ }^{3}$ Объединенный институт высоких температур, Москва, Россия \\ ฯ E-mail: gb-r@mail.ru
}

Поступило в Редакцию 14 апреля 2020г.

В окончательной редакции 20 апреля 2020г.

Принято к публикации 20 апреля 2020 г.

\begin{abstract}
Представлены результаты исследований динамики приэлектродных процессов в начальной фазе искрового разряда в воздухе атмосферного давления в геометрии острие-плоскость. Вблизи поверхности плоского катода после пробоя зарегистрированы области размером около $50 \mu \mathrm{m}$ и более с повышенной концентрацией электронов, составляющей $(3-8) \cdot 10^{19} \mathrm{~cm}^{-3}$. С учетом экспериментальных данных по эрозионному воздействию разряда на поверхность плоского электрода и сопутствующим газодинамическим эффектам предложена физическая модель приэлектродных процессов, на основании которой выполнены оценки газодинамических параметров.
\end{abstract}

Ключевые слова: газовый разряд, микроструктура, прикатодная плазма, ударная волна.

DOI: 10.21883/PJTF.2020.15.49740.18336

Широкое практическое применение и научный интерес стимулируют актуальность исследований импульсных газовых разрядов и обусловливают большое количество публикаций в этом направлении. Вместе с тем ряд явлений до сих пор остается малоизученным. Одно из них связано с наличием микроструктуры токовых каналов и ее участием в газоразрядных процессах в плотных газах, когда канал представляет собой скопление около 100 и более каналов микронного диаметра [1-9]. Микроструктура разрядов регистрировалась методом автографов в виде множества микрократеров на поверхности электродов [1-5] и методом теневого фотографирования в объеме разрядного промежутка [6-9]. При этом оптическими и электронно-оптическими методами внутренняя структура токового канала на фоне светящейся внешней оболочки была неразрешима $[1,2,4]$.

Полученные к настоящему времени данные по микроструктурированным разрядам в плотных газах, во-первых, свидетельствуют о том, что это явление нередкое, а во-вторых, указывают на возможность существенной взаимосвязи микроструктуры и динамики протекающих процессов (см. работы [1-8] и ссылки в них).

Так, в исследованиях по теневому фотографированию искрового разряда вблизи поверхности плоского электрода были зарегистрированы структуры полукольцевой формы, отождествленные с полусферическими ударными волнами (УВ). Было высказано предположение, что источниками УВ являются процессы формирования микрократеров в областях контакта микроканалов с плоским электродом [5,7]. Эрозионные микрократеры при этом имели диаметр от 5 до $35 \mu \mathrm{m}$ и глубину от 0.1 до $0.4 \mu \mathrm{m}[5]$.

Целью настоящей работы является продолжение исследований динамики приэлектродных процессов в начальной фазе микроструктурированного искрового разряда в воздухе атмосферного давления в геометрии острие-плоскость.

Эксперименты проводились на стенде, включающем генератор импульсов напряжения (ГИН), кабельную линию, разрядный промежуток, диагностическую аппаратуру и систему синхронизации. Подробно аппаратура и методики описаны в [5-8].

Генерация импульсов напряжения обеспечивалась коммутацией заряженной емкости ГИН на кабельную линию. Амплитуда напряжения на выходе ГИН составляла $30 \mathrm{kV}$ и имела положительную полярность. Длительность фронта импульса напряжения по уровню $0.1-0.9$ составляла $7 \mathrm{~ns}$.

Кабельная линия длиной $7 \mathrm{~m}$ нагружалась на разрядный промежуток острие-плоскость. В качестве острия использовался осесимметричный электрод длиной $40 \mathrm{~mm}$, диаметром $10 \mathrm{~mm}$ с углом при вершине $14^{\circ}$ и радиусом кривизны $0.1 \mathrm{~mm}$, изготовленный из нержавеющей стали. Межэлектродный зазор составлял $1.5 \mathrm{~mm}$.

В экспериментах измерение напряжения (емкостным делителем) и тока (резистивным шунтом) осуществлялось на выходе ГИН. 

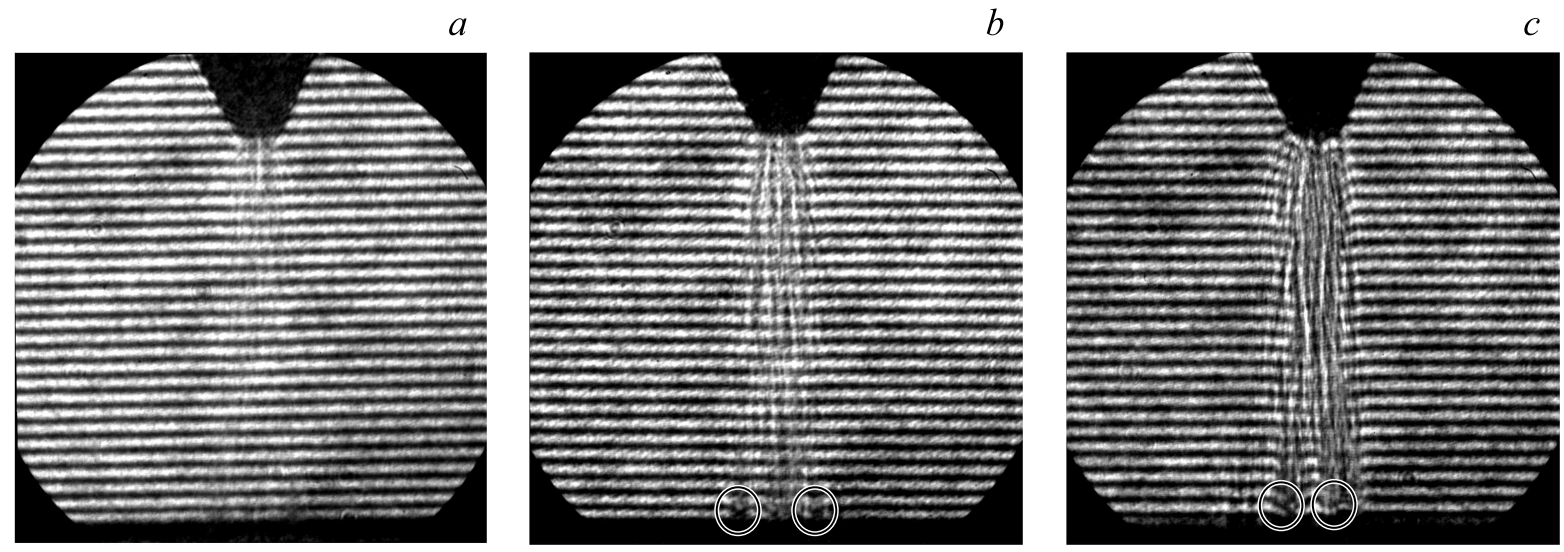

Рис. 1. Интерферограммы разряда в различные моменты времени относительно начала пробоя: $a-2 \mathrm{~ns}, b-5 \mathrm{~ns}, c-8 \mathrm{~ns}$. Электрод-острие находится сверху. Окружностями на частях $b$ и $c$ вблизи катода выделены области сдвига интерференционных полос.

Система оптической регистрации включала в себя источник зондирующего излучения - лазер (длина волны $532 \mathrm{~nm}$, длительность импульса на полувысоте $6 \mathrm{~ns})$, объектив, светофильтры и цифровую электроннооптическую камеру. Плоскопараллельный пучок лазерного излучения, проходя через область разряда перпендикулярно оси электрода-острия, регистрировался электронно-оптической камерой. Система регистрации обеспечивала пространственное разрешение не хуже $5 \mu \mathrm{m}[6-8]$.

С применением описанной системы оптической регистрации и оптической схемы на базе интерферометра Маха-Цендера была реализована интерференционная методика. Экспозиция кадра интерферограммы определялась длительностью импульса лазера.

Сдвигом момента запуска системы оптической регистрации относительно момента пробоя обеспечивалась визуализация различных стадий разрядного процесса. Съемка велась в однокадровом режиме (один кадр за импульс). За момент пробоя был принят момент начала роста тока и соответственно спада напряжения.

На рис. 1 представлены интерферограммы разряда в различные моменты времени. Видно, что аналогично [6-9] разряд развивается в микроканальной форме. Смещение интерференционных полос начинает регистрироваться на $5 \mathrm{~ns}$ после пробоя вблизи плоского электрода и едва заметно вблизи острия. Диаметр канала разряда в этот момент составляет $\sim 0.3 \mathrm{~mm}$, количество микроканалов оценочно $\sim 100$, диаметр микроканалов $\sim 10 \mu \mathrm{m}$, ток разряда $\sim 400 \mathrm{~A}$. Смещение полос отрицательное. В настоящей работе в качестве причины такого смешения рассматривается рефракция на свободных электронах. При этом предполагается, что частота лазерного излучения лежит вдали от частот всех резонансных переходов присутствующих в разряде частиц.

Для интерферограммы на рис. $1, b$ сдвиг интерференционных полос регистрируется на расстояниях вплоть до $100 \mu \mathrm{m}$ от плоского электрода в двух областях. Поперечный по отношению к оси симметрии промежутка размер искажений полос не превышает $50 \mu \mathrm{m}$. Полагая, что этот размер задает оптическую длину пути, можно считать, что определенная по сдвигу полос концентрация электронов в этих областях составляет не менее $3 \cdot 10^{19} \mathrm{~cm}^{-3}$.

Для интерферограммы, соответствующей $8 \mathrm{~ns}$ (рис. 1,c), поперечные размеры областей сдвига полос имеют значения 50-100 $\mu \mathrm{m}$, концентрация электронов в них составляет $(4-8) \cdot 10^{19} \mathrm{~cm}^{-3}$ на расстояниях до $200 \mu \mathrm{m}$ отплоского электрода.

Следует отметить, что после $15 \mathrm{~ns}$ выделяющихся на общем фоне локальных повышенных смещений интерференционных полос в прикатодной области не регистрируется, картина в этой области становится подобной наблюдаемой во всем канале, что связано с ростом и выравниванием концентрации плазмы в нем.

Зарегистрированные уровни концентрации электронов заметно превосходят значения, соответствующие однократной ионизации воздуха, что свидетельствует о наличии в приповерхностной области плоского электрода плазмы его материала. Полученные результаты в целом подтверждают высказанное ранее предположение о процессах формирования микрократеров и их роли в качестве источников генерации ударных волн в микроструктурированном разряде.

На основании полученных данных рассмотрим следующую физическую модель приэлектродных процессов в микроструктурированных разрядах (рис. 2): микрократеры формируются в результате интенсивного нагрева и испарения вещества материала электрода в областях его контакта с микроканалами, что вызывает генерацию УВ.

Оценим скорость распространения полусферической УВ, расходящейся от поверхности плоского электрода в нагретом газе канала разряда. При этом в качестве процесса, обеспечивающего генерацию УВ, рассмотрим испарение материала с поверхности электрода в области 


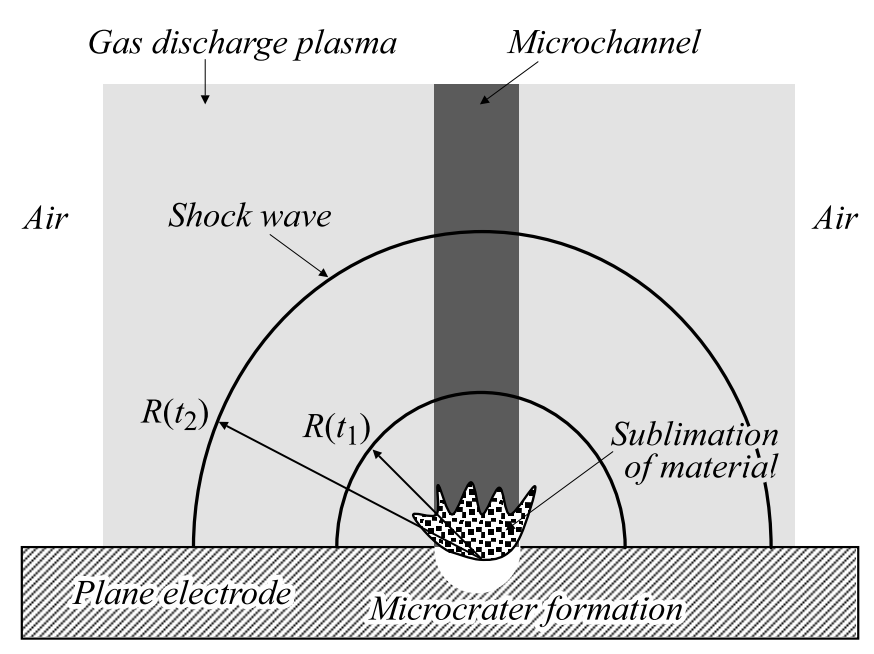

Рис. 2. Схематическая модель приэлектродных процессов в микроструктурированном разряде. Время $t_{1}$ соответствует моменту, когда сильная УВ превращается в звуковое возмущение, $t_{2}$ определяет промежуточное положение УВ $R\left(t_{2}\right)$.

формирующегося микрократера, т. е. энергия, запасенная в испаренном материале в результате формирования микрократера, пойдет на образование УВ. Будем считать этот процесс достаточно быстрым по сравнению с газодинамическими процессами, которые в нашем случае протекают за время порядка $100 \mathrm{~ns}$ [7]. Данное обстоятельство дает возможность рассмотреть газодинамику с мгновенным энерговыделением.

Энерговклад в образование УВ для микрократера диаметром $d=15 \mu \mathrm{m}$ и глубиной $h=0.4 \mu \mathrm{m}$ оценим как

$$
E_{e v}=m_{c r} L \approx d^{2} h \rho L,
$$

где $\rho$ - плотность материала электрода, $m_{c r}-$ масса материала катода, которая испарилась из кратеpa, $L$ - теплота его испарения. Полагая для меди $\rho=8960 \mathrm{~kg} / \mathrm{m}^{3}, L=4.76 \cdot 10^{6} \mathrm{~J} / \mathrm{kg}$, имеем $E_{e v}=4 \mu \mathrm{J}$.

Соотношение давления на фронте сильной УВ $p$ и в невозмущенном газе $p_{0}$ определяется выражением [10]:

$$
\frac{p}{p_{0}}=\frac{2 \gamma_{0}\left(\gamma^{2}-1\right)}{3 \gamma-1} \frac{L}{c^{2}} \frac{m_{c r}}{m},
$$

где $\gamma_{0}$ и $\gamma$ - соответственно значения постоянной адиабаты в невозмущенном газе и за фронтом УВ. В широком диапазоне температур $\left(10^{4}-10^{5} \mathrm{~K}\right)$ для воздуха при нормальной плотности можно принять $\gamma_{0}=\gamma=1.2$ [10]. Масса воздуха, охваченная УВ радиусом $R$, есть

$$
m=\frac{2}{3} \pi R^{3} \rho_{0}
$$

где $\rho_{0}-$ плотность воздуха. Скорость звука в газе с температурой $T$ оценим как

$$
c^{2}=c_{273}^{2} \frac{T}{T_{0}}
$$

где $c_{273}=330 \mathrm{~m} / \mathrm{s}$ - скорость звука в воздухе при температуре $T_{0}=273 \mathrm{~K}$.
Сильная УВ превращается в обычную звуковую волну, когда правая часть уравнения (1) порядка величины $\frac{\gamma+1}{\gamma-1}$ :

$$
\frac{p}{p_{0}}=\frac{2 \gamma_{0}\left(\gamma^{2}-1\right)}{3 \gamma-1} \frac{L}{c^{2}} \frac{m_{c r}}{m}=\frac{\gamma+1}{\gamma-1} .
$$

Соответственно распространение возмущения в канале условно можно разбить на два этапа: движение сильной УВ и распространение звукового возмущения. Радиус сильной УВ определяется выражением

$$
R(t)=\beta\left(\frac{E_{e v}}{\rho_{0}}\right)^{1 / 5} t^{2 / 5}
$$

где коэффициент $\beta$ составляет $\beta=0.89 \cdot 2^{1 / 5}$ для $\gamma=1.2[10]$, множитель $2^{1 / 5}$ появляется из-за того, что волна полусферическая.

В соответствии с экспериментальными данными [7] к моменту времени $\tau=135 \mathrm{~ns}$ радиус УВ составляет около $R_{0}=300 \mu \mathrm{m}$. Соответственно для звукового режима движения волны запишем

$$
\left(\frac{R_{0}-R(t)}{\tau-t}\right)^{2}=c_{273}^{2} \frac{T}{T_{0}}
$$

Решая совместно уравнения (2)-(4), получим для температуры газа в канале значение на уровне $T=10 \mathrm{kK}$. При этом время движения сильной УВ получается равным $t_{1}=2 \mathrm{~ns}$. К этому моменту радиус волны в соответствии с (3) достигает значения $R\left(t_{1}\right)=24 \mu \mathrm{m}$ (рис. 2). Далее сильная УВ вырождается в слабую и распространяется со скоростью звука. Следует отметить, что в эксперименте [7] к моменту времени $t_{2}=30 \mathrm{~ns}$ радиус УВ составлял $100 \mu \mathrm{m}$, при этом расчеты на основе уравнений (2)-(4) дают значение $R\left(t_{2}\right)=83 \mu \mathrm{m}$ (рис. 2), что достаточно близко к экспериментальным данным.

Таким образом, в работе представлены результаты измерения концентрации электронов вблизи плоского электрода в начальной фазе наносекундного искрового разряда в геометрии острие-плоскость. На основании данных по эрозионному воздействию разряда выполнена оценка газодинамических процессов и получено удовлетворительное согласие с экспериментальными данными по динамике ударной волны.

\section{Финансирование работы}

Исследование выполнено при финансовой поддержке Российского фонда фундаментальных исследований в рамках научного проекта № 20-08-01069а.

\section{Конфликт интересов}

Авторы заявляют, что у них нет конфликта интересов. 


\section{Список литературы}

[1] Карелин В.И., Тренькин А.А. // ЖТФ. 2008. Т. 78. В. 3. C. 29-35.

[2] Перминов А.В., Тренькин А.А. // ЖТФ. 2005. Т. 75. В. 9. C. $52-55$.

[3] Репьев А.Г., Репин П.Б., Покровский В.С. // ЖТФ. 2007. T. 77. B. 1. C. $56-62$.

[4] Бакит Е.Х., Блинова О.М., Ерофеев М.В., Карелин В.И., Рипенко В.С., Тарасенко В.Ф., Тренькин А.А., Шибитов Ю.М., Шулепов М.А. // Физика плазмы. 2016. Т. 42. № 9. C. 859-870.

[5] Тренькин А.А. // ЖТФ. 2019. Т. 89. В. 2. С. 189-191.

[6] Алмазова К.И., Белоногов А.Н., Боровков В.В., Горелов Е.В., Морозов И.В., Тренькин А.А., Харитонов С.Ю. // ЖТФ. 2018. Т. 88. В. 6. С. 827-831.

[7] Алмазова К.И., Белоногов А.Н., Боровков В.В., Горелов Е.В., Морозов И.В., Тренькин А.А., Харитонов С.Ю. // ЖТФ. 2019. Т. 89. В. 1. С. 69-71.

[8] Тренькин А.А., Алмазова К.И., Белоногов А.Н., Боровков В.В., Горелов Е.В., Морозов И.В., Харитонов С.Ю. // ЖТФ. 2019. Т. 89. В. 4. С. 512-517.

[9] Parkevich E.V., Medvedev M.A., Ivanenkov G.V., Khirianova A.I., Selyukov A.S., Agafonov A.V., Korneev Ph.A., Gus'kov S.Y., Mingaleev A.R. // Plasma Sources Sci. Technol. 2019. V. 28. N 9. P. 095003.

[10] Райзер Ю.П. Введение в гидрогазодинамику и теорию ударных волн для физиков. М.: Интеллект, 2011. 432 с. 